\title{
Health Benefits Derived from Forest: A Review
}

\author{
Gianluca Grilli ${ }^{1,2,3}$ and Sandro Sacchelli ${ }^{1, *}$ \\ 1 Department of Agriculture, Food, Environment and Forestry, University of Florence, I-50144 Florence, Italy; \\ Gianluca.Grilli@esri.ie \\ 2 Economic and Social Research Institute, D02 K138 Dublin, Ireland \\ 3 Trinity College Dublin, D02 PN40 Dublin, Ireland \\ * Correspondence: sandro.sacchelli@unifi.it
}

Received: 17 July 2020; Accepted: 21 August 2020; Published: 23 August 2020

check for updates

\begin{abstract}
In this paper the scientific literature on the association between forests, stress relief and relaxation is reviewed with the purpose to understand common patterns of research, the main techniques used for analysis, findings relevant to forest-therapy-oriented management, and knowledge gaps. The database of studies was collected with a keyword search on the Web, which returned a set of 32 studies that were included in the analysis. The main findings and patterns were identified with a text mining analysis of the abstract to search for keyword patterns across studies. The analysis indicates that most studies compared rest and relaxation performances across urban and forest environments and used a combination of self-reported measure of stress or rest collected with validate scales, e.g., the Profile of Mood of States (POMS) and the Restoration Outcome Scale (ROS), and a minority-only set of these two groups of indicators. Results of this review indicate that primary studies identified a positive association between forest exposure and mental well-being, in particular when compared to urban environments, thus suggesting that forest are effective in lowering stress levels. This study found that, to date, the characteristics of forests and characteristics of the visit are little investigated in the literature. For this reason, more research with a focus on forest variables such as tree species composition, tree density and other variables affecting forest landscape should be further investigated to inform forest management. Similarly, the characteristics of the visits (e.g., length of visit and frequency) should be further explored to provide robust forest therapy guidelines.
\end{abstract}

Keywords: forest therapy; forest recreation; relaxation; stress relief; quantitative analysis; psycho-physiological indicators

\section{Introduction}

Recreation is a very important ecosystem service provided by natural areas. In particular, forested areas provide countless recreational opportunities such as hiking, picnicking, mushroom and berry picking, biking and horse riding. For this reason, there is an increasing trend in forest management to leave some forested areas as dedicated areas for recreation. The propensity of a forest for recreation is highly specific [1]. Previous research highlighted the importance of forest structure for recreation; in particular, it has been observed that tree species composition, forest cover and forest structure are important variables [2,3]. With respect to forest types, mixed and coniferous forests are often preferred destinations for recreational purposes compared to broadleaf forests [4,5], while canopy cover has been found to influence recreation based on transport and access to forests, with lower canopy cover preferred by motorized recreationalists and higher density cover by non-motorized visitors [6]. The other examined preference studies linked forest structure in terms of shrubs, dead wood, and type of higher trees to different preferences in terms of recreational activities [7].

One of the recent trends in the recreational aspects of forest management is to explore the potential of woodlands for stress relief and rest. This is especially important for forested areas in proximity 
of cities. Urban areas are increasingly seen as a source of stress, because industrialized society has created a frenetic routine for individuals. Urbanization is increasing, particularly in some developing nations, and, as a result, it is estimated that $67 \%$ of the world population will be living in urban areas by 2050 [8]. Easy access to oases where one can rest and that are close to urban areas is important for resting the mind and mental well-being. The health benefits of being in contact with nature are demonstrated by several studies, many of which were collected in the meta-analysis published by Gascon et al. [9]. More recently, a study in England found that spending 120 min per week in nature is sufficient to maintain good health and well-being levels [10]. The benefits of green areas for well-being are not necessarily linked to active visitation, as the simple exposure to natural environments is equally beneficial. In fact, several hospitals are now equipped with the so-called "healing gardens", where patients can spend some time to recover from mental diseases [11-13]. Due to the close link of stress to urban life, most studies analyse the impact of within-city green spaces on mental well-being. Bowler et al. [14] collected all studies specifically designed to understand the effect of urban green spaces on rest in a systematic meta-analysis and found that all primary sources identified some degree of effectiveness of green spaces on human health. While urban green spaces are recognized environments where one can rest, the potential of close-to-city forests for therapy is less explored, and little effort has been dedicated to gather the existing scientific evidence to identify lessons learned and knowledge gaps.

With this in mind, this contribution offers a review of the literature exploring the association between forest exposure and mental well-being, in particular with respect to relaxation or rest from stress. The main objective of the paper is to provide a snapshot of the existing knowledge, techniques and approaches implemented to study forest therapy. The analysis considers stress indicators, forest stands, and forest characteristics associated with relaxation, as well as interesting avenues for future research. Results are useful to indicate development paths for forest managers interested in forest therapy and to inform researchers and analysis on evidence that is still missing on this relevant topic.

\section{Materials and Methods}

\subsection{Database Collection}

The data collection was carried out with a keyword search in Scopus, i.e., one of the largest scientific databases available. Scopus was chosen because it is user-friendly and large enough to include most papers indexed in other famous servers, for example Web of Science. A preliminary qualitative study of four papers relevant to the topic [15-18] was undertaken to familiarize with the specific nomenclature and select the most appropriate keywords. The keyword search was then conducted using one word among "forest", "woodlands" or "greenwoods" in combination with one of the following: "therapy", "stress", "relaxation", "restoration", "bathing" (the Scopus search was conducted on 7th August 2020 with the following string: (TITLE-ABS-KEY (forest) OR TITLE-ABS-KEY (woodlands) OR TITLE-ABS-KEY (greenwoods) AND TITLE-ABS-KEY (therapy) AND TITLE-ABS-KEY (stress) OR TITLE-ABS-KEY (restoration) OR TITLE-ABS-KEY (relaxation) OR TITLE-ABS-KEY (bathing)). The criteria for the inclusion of a contribution were the following: (1) the paper must be focused on benefits obtained from exposure to forests; (2) the paper must explore the effects of relaxation or rest of forests; (3) the paper must follow a treatment-control experiment approach; (4) the paper must use self-rated or physiological indicators of stress/rest. These criteria were used to obtain a homogeneous set of manuscripts, which were comparable in terms of topic and methodological approach. Manuscripts that did not satisfy all of these selection criteria were excluded from the analysis. For example, many contributions concentrate on urban green spaces because they are important for rest from city life. A large list of these papers has been collected previously [14]. Since one of the main objectives of this review is to provide indications for therapy-oriented forest management, urban green space papers were excluded due to the limited usefulness for forest management purposes. Finally, both quantitative (based on text mining approach) and qualitative reviews (focused on the 
applied methods, the effects of relaxation and rest of forests as well as influence of forest characteristics on stress recovery) were performed (Figure 1).

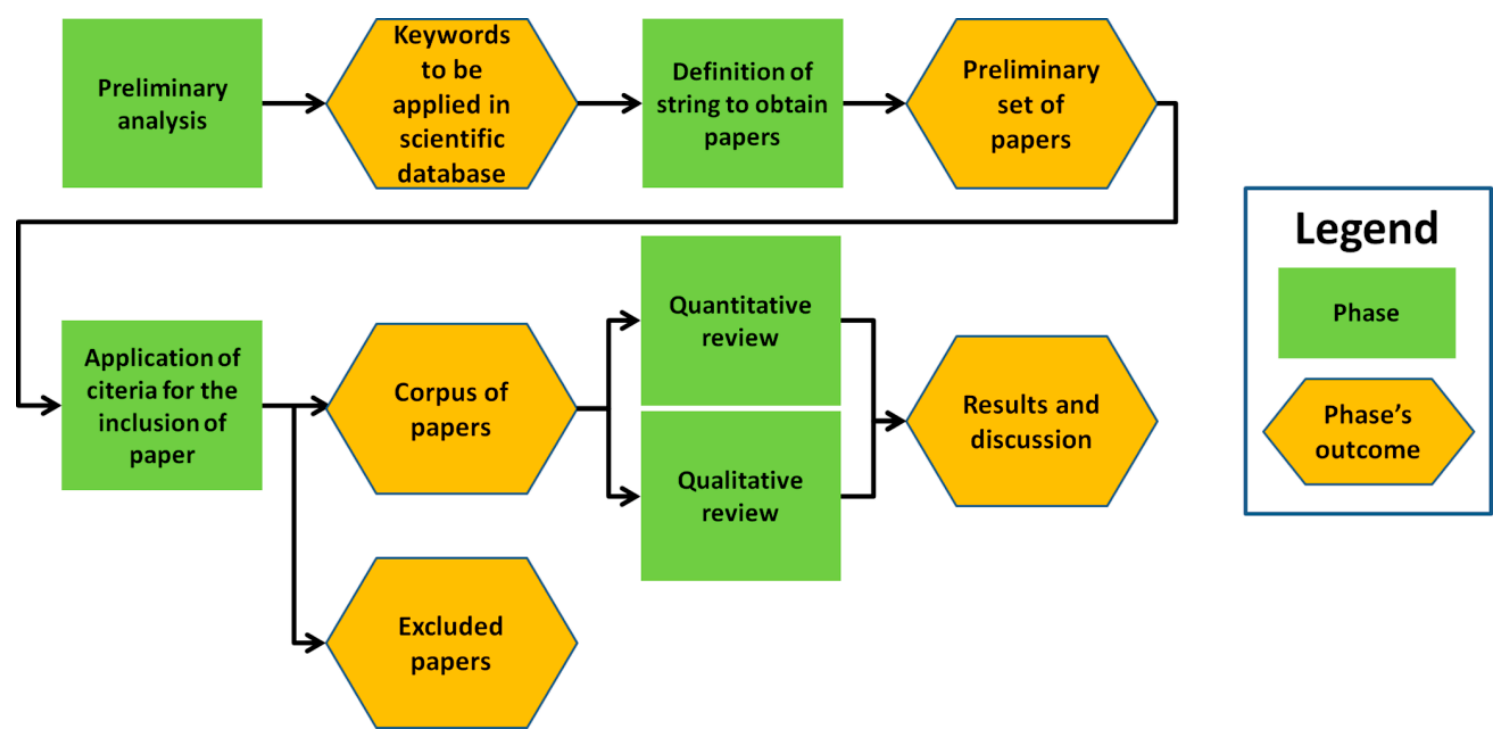

Figure 1. General methodological framework of the study.

\subsection{Text Mining Analysis}

A quantitative evaluation was performed to integrate the qualitative literature analysis, which should be considered as a preliminary test to be integrated in future evaluations. This quantitative analysis is a text mining exercise based on the title, abstract and keyword of all examined papers (corpus). The corpus was imported as a .txt file and text mining was performed by means of the software T-Lab (www.tlab.it), a tool based on the lexicometric approach [19]. Based on the big data framework, text mining derives patterns within the corpus such as in clustering, concept extraction and sentiment analysis. In our work, we used the multidimensional scaling approach (MDS) [20]. In MDS, through the application of Sammon's algorithm [20], relationships among lemmas in the corpus are represented in a graphical way (distance and position). Lemmas are denoted by circles of single or aggregated words. The size of the circle highlights the weights of the lemma in the corpus. The significance of the MDS map is revealed by the stress index that measures the difference between the observed dissimilarity matrix among the lemmas and the estimated one.

\section{Results and Discussion}

The search provided an initial list of 162 documents, but many papers did not satisfy all the considered criteria. After reading the abstracts, the list of documents was further cleared, and the final set included 36 papers, which were homogeneously organized and adequate for the purpose of this review. Most self-reported scales used in primary studies are known in the scientific literature with acronyms and abbreviations, which are reported in Table 1 . The full list of study is shown in Table 2. Out of these documents, 24 were carried out considering measures regarding self-rated stress or rest, 27 focused on physiological measures, and 17 used both approaches. Most contributions were recent, with only one paper published before 2002; this indicates that scientific attention on forest therapy and stress reduction is a very new topic. In terms of experimental settings, most studies involved on-site data collection, which means that the recruited sample was brought to the forest to allow forest immersion. A smaller share of experiments were conducted in a lab setting by means of virtual reality (VR) devices that simulated natural environments. 
Table 1. Acronym of self-rated indicators used in primary studies.

\begin{tabular}{cc}
\hline Nomenclature & \\
\hline PANAS & Positive And Negative Affect Schedule \\
POMS & Profile Of Mood States \\
SVS & Subjective Vitality Scale \\
PSS & Perceived Stress Scale \\
RAND 36 & Emotional well-being scale \\
SDM & Semantic differential method \\
TMD & Total mood disturbance \\
STAI & State-Trait Anxiety Inventory \\
ROS & Restoration Outcome Scale \\
MBI & Maslach Burnout Inventory \\
\hline
\end{tabular}

Figure 2 shows the geographical distribution of the studies. Japan is the most represented country with 10 studies. China and the USA are represented by six and five studies, respectively, while South Korea, Finland and Poland each have three studies. Other countries where forest therapy studies were conducted are Italy, Sweden, Switzerland and Taiwan, all with a smaller number of one or two studies.

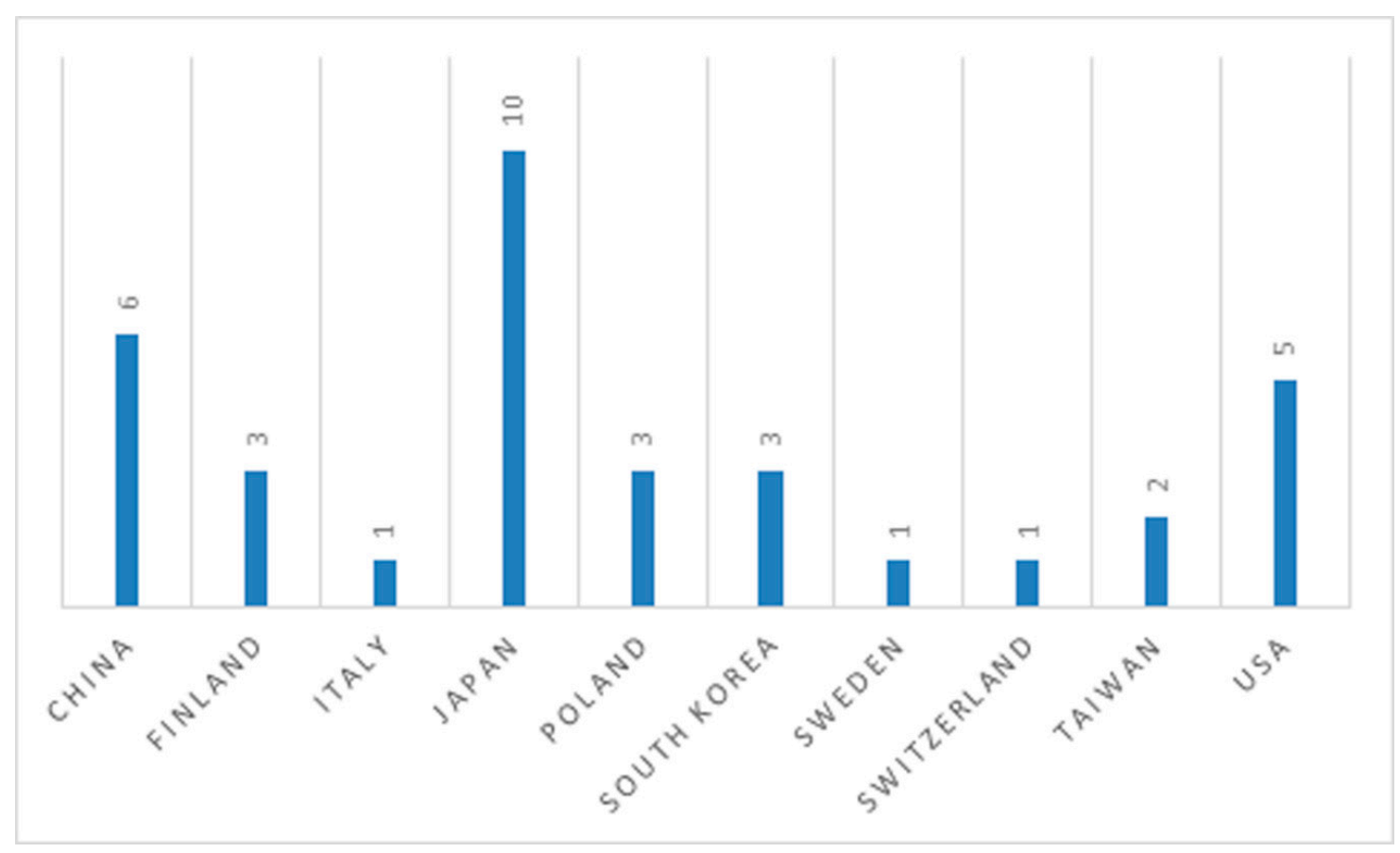

Figure 2. Geographical distribution of the studies. 
Table 2. Studies included in the review.

\begin{tabular}{|c|c|c|c|c|}
\hline Authors & Year & Source & Self-Rated Measures & Physiological Measures \\
\hline Ulrich et al. & 1991 & [17] & - & blood pressure, muscle tension \\
\hline Hartig et al. & 2003 & [21] & - & blood pressure \\
\hline Hansmann et al. & 2007 & [22] & non-validated measures & - \\
\hline Park et al. & 2007 & [23] & - & cortisol, electroencephalography (EEG) \\
\hline Park et al. & 2008 & [24] & - & cortisol, heart beat \\
\hline Park et al. & 2009 & & - & cortisol, heart beat \\
\hline Li et al. & 2012 & [25] & POMS & blood pressure, heart beat, urine dopamine, and cardiovascular and metabolic parameters \\
\hline Annerstedt et al. & 2013 & [26] & - & cortisol, cardiovascular data \\
\hline Beil and Hanes & 2013 & [18] & PSS & cortisol \\
\hline Tsunetsugu et al. & 2013 & [27] & POMS, ROS & blood pressure, heart beat, nervous activity \\
\hline Jiang et al. & 2014 & [28] & - & cortisol, skin conductance \\
\hline Korpela et al. & 2014 & [29] & RAND 36 & \\
\hline Tirvainen et al. & 2014 & [30] & ROS & cortisol \\
\hline Jung et al. & 2015 & [31] & MBI & cortisol, heartbeat, natural killer cell \\
\hline Ochiai et al. & 2015 & [32] & SDM, POMS, TMD & blood pressure \\
\hline Chiang et al. & 2017 & [33] & POMS & EEG \\
\hline Ohe et al. & 2017 & [34] & POMS & blood pressure, heart beat \\
\hline Park et al. & 2017 & [35] & PANAS & heart rate, prefrontal cortex activity \\
\hline Song et al. & 2017 & [36] & SDM & heartbeat, blood pressure \\
\hline Bielinis & 2018 & [37] & PANAS, POMS, ROS, SVS & \\
\hline Chen et al. & 2018 & [38] & POMS, STAI & salivary amylase, blood pressure, heart beat \\
\hline Bielinis et al. & 2019 & [39] & ROS, POMS & blood pressure, heartbeat \\
\hline Lee et al. & 2019 & [40] & non-validated measures & - \\
\hline Song et al. & 2019 & [41] & POMS, STAI & nervous activity, heartbeat \\
\hline Wang et al. & 2019 & [42] & POMS & \\
\hline Chia-Pin and Hsieh & 2020 & [43] & POMS, TMD & \\
\hline Huang et al. & 2020 & [44] & - & skin conductance \\
\hline Kim et al. & 2020 & [45] & POMS & \\
\hline Kuper & 2020 & [46] & - & heartbeat, blood pressure \\
\hline Sacchelli et al. & 2020 & [47] & ROS & EEG \\
\hline Janeczko et al. & 2020 & [48] & POMS, PANAS, ROS, SVS & heart rate, blood pressure \\
\hline Zeng et al. & 2020 & [49] & SDM & peripheral oxygen saturation, heartbeat, blood pressure \\
\hline Jiang & 2020 & [50] & - & EEG, skin conductance, heartbeat, blood pressure \\
\hline Bielinis et al. & 2020 & [51] & fluid procrastination & - \\
\hline Wang and Zao & 2020 & [52] & - & EEG \\
\hline
\end{tabular}




\subsection{Quantitative Review (Text Analysis)}

The stress index of MDS output (0.092) indicates a positive correlation between the input matrix and Sammon's map [53].

The map displayed in Figure 3 shows that research interest has, to date, concentrated on some topics. In the first quadrant, the influence of forest variables on stress relief is shown. Lemmas such as "tree" or "density" are related to "restoration" effects or "preference" of people. The "attention" level of interviewees as to the "exposure" to forests, in particular through the so-called "dose-response" effect are investigated with particular care. Forest seasonality was very influential on stress recovery (due to lemmas "season", "foliage", "evergreen", "winter" or specification of month of the year). Immersion of people in forests—on-site or using new "virtual" reality technologies—is indicated on the map. Some studies report the importance of the "sound" of forests for stress recovery (analyzed in literature, particularly in "park" and urban green areas). The second quadrant focuses on a cluster of lemmas related to physiological indicators of "well-being". Some scientific papers use "cardiovascular" parameters, "salivary cortisol", "prefrontal" performances (i.e., activity in highly stress-related area of brain) or "parasympathetic" nervous system activation to define the status of people in the case of forest exposition. Forest variables are included in the specific sense of "view" and "landscape" evaluation. Activities ("walk") and performances ("concentration") are investigated in general terms ("subject") or for specific age and status ("student"). An interesting topic appears in this quadrant, that is, the "tourism" tendency of forest bathing ("Shinrin-yoku") is emphasized, particularly for "Japan". Undertaking analyses at different times of the day seems to be relevant for stress recovery ("morning" and "afternoon" lemmas). The third quadrant introduces the basic concept linked to "forest", "therapy", "health" and "anxiety" as well as the evaluation of the most investigated "physiological" parameters ("heart rate" and "nervous" trend). However, a focus on psychological analysis is here outlined by the terms "score" (typical of questionnaires), "mood" and "POMS" scale. The last quadrant also designates a cluster composed by general lemmas describing both psychological ("questionnaire", "scale") and physiological ("systolic") terms, interviewed group ("young", "adult") and area ("Taiwan"). The preliminary text mining is based on a limited number of papers in respect to the existing application of similar methods in the literature [54]; however, it provides a good comparison with qualitative literature reviews described in this paper, facilitating replicability of the analysis for different countries or temporal trends. In future works, additional quantitative evaluation could be introduced.

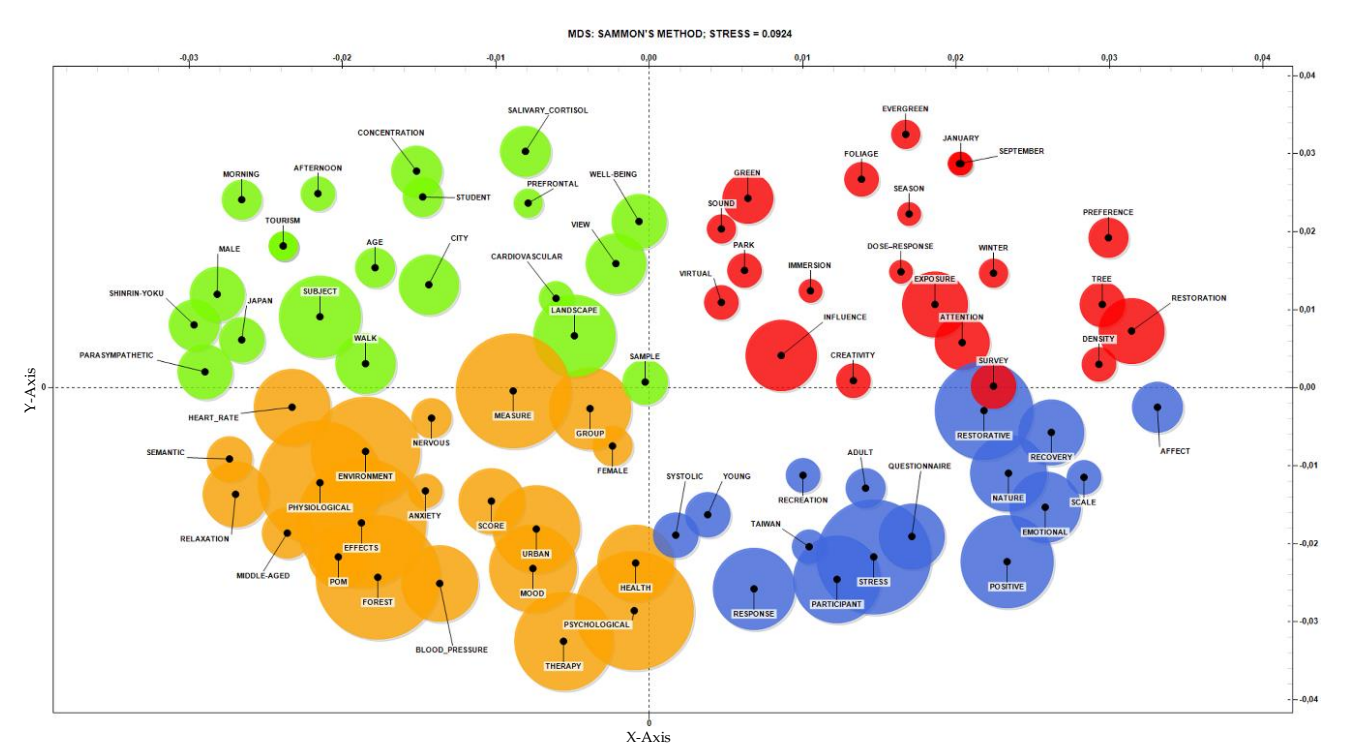

Figure 3. Sammon's map showing relationships among lemmas (different colours denote the four quadrants). 


\subsection{Performance Measurement}

The effectiveness of forests for relaxation and rest compared to urban areas or control groups has been tested with two families of indicators: (1) self-rated measures and (2) physiological outcomes.

Self-rated measures are subjective answers of participants to a set of questions that capture the perceived mood after stimuli administration. There are several ready-to-use questionnaires for this purpose. The most common scale in the sample was the Profile Of Mood States (POMS), whose purpose is to evaluate individual moods associated with certain forest exposure [37-39]. The Positive And Negative Affect Schedule (PANAS) is instead one of the oldest but not so popular scales available [55], and was used by Bielinis et al. [37,51] and Park et al. [36] for the evaluation of the therapeutic effects of forests. The evaluation of rest is conducted with a specific scale called the Restoration Outcome Scale (ROS), which is composed of six items [56]. In the forest therapy literature, the use of ROS is relatively popular $[27,30,37,39,47]$. Less popular measures are the Subjective Vitality Scale (SVS) [37], the Perceived Stress Scale (PSS) [37], the emotional well-being scale (RAND 36) [29], the semantic differential method (SDM) [32], total mood disturbance (TMD) [32], the Maslach Burnout Inventory (MBI) [31] and the restored ability to work (RAW) [57]. Interestingly, one contribution investigated, among other indicators, the "fluid procrastination", which indicates a pessimistic attitude to complete a job. The psychological stress measure (PSM-9) is a popular approach to measure stress [58], which uses a set of nine indicators; however, none of the studies considered in this review implemented investigations based on PSM-9. This result is a potential indication that most research in forest therapy considered rest potential and mood induced by forests with specific scales such as POMS and ROS, rather than measures of stress levels. Lastly, some papers captured self-rated measures with scales that were not previously validated in the literature [22,40].

With respect to physiological measures, saliva samples for cortisol and amylase represent the most common indicator $[18,24,26,28,30,31,38]$. Two main other measures are blood pressure and heartbeat $[17,21,25,34,37]$. Often cortisol, blood pressure and heartbeat are measured simultaneously. Interestingly a minority of other contributions utilized indicators of natural killer cells [31]. Another important indicator of stress is the analysis of cerebral activity, collected with electroencephalogram devices $[33,47,52]$.

\subsection{Forests' Effects of Relaxation and Rest}

An initial interesting result is that all studies report a positive impact of exposure to forest environments on measures related to stress and rest, regardless of the indicator used. Several Japanese studies, where forest therapy is often referred to as "Shinrin-yoku" (taking in the atmosphere of the forest), indicate that spending time in forests helps in reducing cortisol levels and blood pressure, as well as contributing to a more stable heartbeat $[16,23,24]$. Several Chinese studies confirmed a positive association between stress relief and forest recreation [27,32,59]. Moving to Europe, in Nordic countries, numerous studies demonstrated that in experiments that compare stress levels between urban areas and forests, participants always show lower stress levels when exposed to forested areas $[29,30]$. Similar findings were obtained in Italy using a combination of virtual reality, EEG and ROS scales [47]. Another interesting application of virtual reality was offered by Annerstedt et al. [26], who compared three groups exposed to an urban setting, a forest and a forest including sounds of nature, respectively. Results indicated that forest relaxation is highest when coupled with sounds of nature. Beil and Hanes conducted a study in the USA where relaxation effects were also confirmed [18].

While no studies reported a failure of forest for relaxation, some studies reported a bad performance of some of the indicators, in particular those related physiological outcome. Two studies in particular reported a negligible or absent effect of forest exposure on lowering saliva cortisol levels $[18,30]$. Authors attributed the result to the short duration of the stimuli, arguing that cortisol response to external stimuli is slow, and that it requires long exposure of respondents to the treatments. 


\subsection{Influence of Forest Characteristics}

Results indicated that, to date, most scientific attention has concentrated on stress levels associated with the urban-forest dichotomy, and that all contributions confirm good forest performance in relation to stress reduction. However, forests are not all the same and vary based on tree species composition, structure, canopy cover, dead wood and other variables that shape forest landscapes. Therefore, the potential of forests to relieve stress may be unevenly distributed across different forest stands, with some forests more appropriate than others. In this respect, the literature is scarcer of contributions, and only five studies collected in this review considered forest characteristics in their experimental design. A pioneer study in this regard was made by Ulrich et al. [17], who compared blood pressure and muscle tension of participants across six different forests. However, the study did not consider single forest characteristics and focused only on different types of forest landscape. Forest density was considered by Chiang et al. [33], whose results indicated that forest density correlates with stress levels. In their study, high density forests caused higher attention levels of participants, but medium density forests were reported to be favoured according to self-rated measures. Bielinis et al. investigated seasonal variations of forest stands for stress recovery, comparing the results of forest therapy between spring and winter [37]. Sacchelli et al. [47] implemented a virtual reality study where four different forest types were compared in winter, and they found that coniferous forests and Douglas fir in particular were more appropriate for stress relief purposes. In China, another virtual reality study by Wang and Zhao [52] confirmed that evergreen trees are more effective to maximize the stress relief potential of forests.

\section{Knowledge Gaps}

Despite a few number of papers currently focusing on the topic "forests for therapy", from a methodological point of view, additional quantitative evaluation could be introduced, especially in the case of largely investigated techniques (e.g., scales applied in questionnaires, neuroscientific tools, visitors preferences, etc.). Text mining gives an objective picture of the analyzed theme, facilitating the summary and extraction of take-home messages. It allows replicability in different times and for a diversified study area. However, a specific guideline on how to use the potentially large amount of available grey literature about forests and health should also be defined.

A certain lack of knowledge is detected in regard to the social benefits-derived from forest activities-that influence mental and physical well-being of individuals, such as strengthening or developing new social relationships [60]. Specific attention should be paid to the dose-response effect, concentrating in particular on differences between application of psychological and physiological measurement of stress relief as well as on the influence of frequency and duration of activities.

A final remark is related to the potential negative impacts of forests on people's health. That is, risks due to allergenic reactions, pests, insects, falling branches and trees or wildfires should be considered-in particular in rural-urban interfaces-to allow the investigation of trade-offs among ecosystem services and disservices.

\section{Conclusions}

The issue of forest characteristics is relevant because the simple comparison of urban versus forest environments provides very little information to forest management. The available scientific evidence gives little information on the fundamental managerial question "How should the forest be managed to increase forest therapy potential?" For this reason, more research on forest characteristics associated with relaxation is necessary to better inform forest-therapy-oriented management. This aspect concerns forest types and tree species composition as well as age structure, cover density, amount of deadwood and, more generally, all the variables that have an impact on forest landscape. 
Author Contributions: Conceptualization, Section 2.2, Section 3.1, supervision and funding acquisition, S.S.; Introduction, Section 2.1, Section 3, Section 3.2, Section 3.3, Section 3.4, G.G.; Section 4, S.S. and G.G. in equal parts. All authors have read and agreed to the published version of the manuscript.

Funding: This study was conducted in the frame of the "Pianificazione strategica di impresa per la valorizzazione sostenibile delle filiere e dei servizi ecosistemici forestali", Grant number: Research fund 2017 n.18080, project, co-financed by Fondazione Cassa di Risparmio di Firenze.

Conflicts of Interest: The authors declare no conflict of interest. The funder had no role in the design of the study; in the collection, analyses, or interpretation of data; in the writing of the manuscript, or in the decision to publish the results.

\section{References}

1. Pukkala, T.; Kellomäki, S.; Mustonen, E. Prediction of the amenity of a tree stand. Scand. J. Res. 1988, 3, 533-544. [CrossRef]

2. Edwards, D.; Jay, M.; Jensen, F.S.; Lucas, B.; Marzano, M.; Montagné, C.; Peace, A.; Weiss, G. Public preferences for structural attributes of forests: Towards a pan-European perspective. Policy Econ. 2012, 19, 12-19. [CrossRef]

3. Paletto, A.; De Meo, I.; Grilli, G.; Nikodinoska, N. Effects of different thinning systems on the economic value of ecosystem services: A case-study in a black pine peri-urban forest in Central Italy. Ann. Res. 2017, 60. [CrossRef]

4. Grilli, G.; Paletto, A.; De Meo, I. Economic Valuation of Forest Recreation in an Alpine Valley. Balt. For. 2014, 20, 167-175.

5. Paletto, A.; De Meo, I.; Cantiani, M.G.; Maino, F. Social Perceptions and Forest Management Strategies in an Italian Alpine Community. Mt. Res. Dev. 2013, 33, 152-160. [CrossRef]

6. Olson, L.E.; Squires, J.R.; Roberts, E.K.; Miller, A.D.; Ivan, J.S.; Hebblewhite, M. Modeling large-scale winter recreation terrain selection with implications for recreation management and wildlife. Appl. Geogr. 2017, 86, 66-91. [CrossRef]

7. Giergiczny, M.; Czajkowski, M.; Żylicz, T.; Angelstam, P. Choice experiment assessment of public preferences for forest structural attributes. Ecol. Econ. 2015, 119, 8-23. [CrossRef]

8. UN. World Urbanization Prospects: The 2014 Revision, Highlights. United Nations, Dep Econ Soc Aff (UN/DESA), Popul Div United Nations Publ. Available online: Https//Esa.Un.Org/Unpd/Wup/Publications/ Files/WUP2014-Highlights.Pdf (accessed on 22 August 2020).

9. Gascon, M.; Zijlema, W.; Vert, C.; White, M.P.; Nieuwenhuijsen, M.J. Outdoor blue spaces, human health and well-being: A systematic review of quantitative studies. Int. J. Hyg. Environ. Health 2017, 220, 1207-1221. [CrossRef]

10. White, M.P.; Alcock, I.; Grellier, J.; Wheeler, B.W.; Hartig, T.; Warber, S.L.; Bone, A.; Depledge, M.H.; Fleming, L.E. Spending at least 120 minutes a week in nature is associated with good health and wellbeing. Sci. Rep. 2019, 9, 1-11. [CrossRef]

11. Jiang, S. Therapeutic landscapes and healing gardens: A review of Chinese literature in relation to the studies in western countries. Front. Arch. Res. 2014, 3, 141-153. [CrossRef]

12. Pouya, S.; Demİel, Ö. What is a healing garden? Akdeniz Üniversitesi Ziraat Fakültesi Derg. 2015, 28 , 5-10.

13. Naderi, J.R.; Shin, W.-H. Humane design for hospital landscapes: A case study in landscape architecture of a healing garden for nurses. Herd Health Environ. Res. Des. J. 2008, 2, 82-119. [CrossRef] [PubMed]

14. Bowler, D.E.; Buyung-ali, L.M.; Knight, T.M.; Pullin, A.S. A systematic review of evidence for the added benefits to health of exposure to natural environments. BMC Public Health 2010, 10, 456. [CrossRef] [PubMed]

15. Bielinis, E.; Takayama, N.; Boiko, S.; Omelan, A.; Bielinis, L. The effect of winter forest bathing on psychological relaxation of young Polish adults. Urban For. Urban Green. 2018, 29, 276-283. [CrossRef]

16. Park, B.J.; Tsunetsugu, Y.; Kasetani, T.; Kagawa, T.; Miyazaki, Y. The physiological effects of Shinrin-yoku (taking in the forest atmosphere or forest bathing): Evidence from field experiments in 24 forests across Japan. Environ. Health Prev. Med. 2010, 18-26. [CrossRef]

17. Ulrich, R.; Simons, R.; Losito, B.; Fiorito, E.; Miles, M.A.; Zelson, M. Stress recovery During Expositure to Natural and Urban Environments. J. Environ. Psychol. 1991, 11, 201-230. [CrossRef]

18. Beil, K.; Hanes, D. The Influence of Urban Natural and Built Environments on Physiological and Psychological Measures of Stress-A Pilot Study. Int. J. Environ. Res. Public Health 2013, 1250-1267. [CrossRef] 
19. Bolasco, S. Analisi Multidimensionale dei Dati: Metodi, Strategie e Criteri D'interpretazione; Carocci: Rome, Italy, 2002; ISBN 8843014013.

20. Sammon, J.W. A nonlinear mapping for data structure analysis. IEEE Trans. Comput. 1969, 100, 401-409. [CrossRef]

21. Hartig, T.; Evans, G.W.; Jamner, L.D.; Davis, D.S.; Tommy, G. Tracking restoration in natural and urban field settings. J. Environ. Psychol. 2003, 23, 109-123. [CrossRef]

22. Hansmann, R.; Hug, S.; Seeland, K. Restoration and stress relief through physical activities in forests and parks. Urban For. Urban Green. 2007, 6, 213-225. [CrossRef]

23. Park, B.J.; Tsunetsugu, Y.; Kasetani, T.; Hirano, H.; Kagawa, T.; Sato, M.; Miyazaki, Y. Physiological effects of Shinrin-yoku (taking in the atmosphere of the forest)-Using salivary cortisol and cerebral activity as indicators. J. Physiol. Anthr. 2007, 26, 123-128. [CrossRef] [PubMed]

24. Park, B.; Tsunetsugu, Y.; Ishii, H.; Furuhashi, S.; Hirano, H.; Kagawa, T.; Miyazaki, Y. Physiological effects of Shinrin-yoku ( taking in the atmosphere of the forest ) in a mixed forest in Shinano Town, Japan. Scand. J. For. Res. 2008. [CrossRef]

25. Li, Q.; Otsuka, T.; Kobayashi, M.; Wakayama, Y.; Inagaki, H.; Katsumata, M.; Hirata, Y.; Li, Y.; Hirata, K.; Shimizu, T.; et al. Effects of forest environments on cardiovascular and metabolic parameters. For. Med. 2012, 2016, 117-136.

26. Annerstedt, M.; Jönsson, P.; Wallergård, M.; Johansson, G.; Karlson, B.; Grahn, P.; Marie, Å.; Währborg, P. Physiology \& Behavior Inducing physiological stress recovery with sounds of nature in a virtual reality forest-Results from a pilot study. Psychol. Behav. 2013, 118, 240-250.

27. Tsunetsugu, Y.; Lee, J.; Park, B.; Tyrväinen, L.; Kagawa, T.; Miyazaki, Y. Landscape and Urban Planning Physiological and psychological effects of viewing urban forest landscapes assessed by multiple measurements. Landsc. Urban Plan. 2013, 113, 90-93. [CrossRef]

28. Jiang, B.; Chang, C.Y.; Sullivan, W.C. A dose of nature: Tree cover, stress reduction, and gender differences. Landsc. Urban Plan. 2014, 132, 26-36. [CrossRef]

29. Korpela, K.; Borodulin, K.; Neuvonen, M.; Paronen, O.; Tyrväinen, L. Analyzing the mediators between nature-based outdoor recreation and emotional well-being. J. Environ. Psychol. 2014, 37, 1-7. [CrossRef]

30. Tyrväinen, L.; Ojala, A.; Korpela, K.; Lanki, T.; Tsunetsugu, Y. The in fl uence of urban green environments on stress relief measures: A field experiment. J. Environ. Psychol. 2014, 38, 1-9. [CrossRef]

31. Jung, W.H.; Woo, J.M.; Ryu, J.S. Effect of a forest therapy program and the forest environment on female workers' stress. Urban For. Urban Green. 2015, 14, 274-281. [CrossRef]

32. Ochiai, H.; Ikei, H.; Song, C.; Kobayashi, M.; Miura, T.; Kagawa, T.; Li, Q.; Kumeda, S.; Imai, M.; Miyazaki, Y. Physiological and psychological effects of a forest therapy program on middle-aged females. Int. J. Environ. Res. Public Health 2015, 12, 15222-15232. [CrossRef]

33. Chiang, Y.-C.; Li, D.; Jane, H.-A. Wild or tended nature? The effects of landscape location and vegetation density on physiological and psychological responses. Landsc. Urban Plan. 2017, 167, 72-83. [CrossRef]

34. Ohe, Y.; Ikei, H.; Song, C.; Miyazaki, Y. Evaluating the relaxation effects of emerging forest-therapy tourism: A multidisciplinary approach. Tour. Manag. 2017, 62, 322-334. [CrossRef]

35. Park, S.-H.; Yeon, P.-S.; Hong, C.-W.; Yeo, E.-H.; Han, S.-M.; Lee, H.-Y.; Lee, H.-J.; Kang, J.-W.; Cho, H.-S.; Kim, Y.-H. A Study on the effect of the forest healing programs on teachers' stress and PANAS. Korean J. Environ. Ecol. 2017, 31, 606-614. [CrossRef]

36. Park, S.A.; Song, C.; Oh, Y.A.; Miyazaki, Y.; Son, K.C. Comparison of Physiological and Psychological Relaxation Using Measurements of Heart Rate Variability, Prefrontal Cortex Activity, and Subjective Indexes after Completing Tasks with and without Foliage Plants. Int. J. Environ. Res. Public Health 2017, 14, 1087. [CrossRef] [PubMed]

37. Bielinis, E.; Omelan, A.; Boiko, S.; Bielinis, L. The Restorative Effect of Staying in a Broad-Leaved Forest on Healthy Young Adults in Winter and Spring. Balt. For. 2018, 24, 218-227.

38. Chen, H.T.; Yu, C.P.; Lee, H.Y. The effects of forest bathing on stress recovery: Evidence from middle-aged females of Taiwan. Forests 2018, 8, 403. [CrossRef]

39. Bielinis, E.; Bielinis, L.; Krupińska-Szeluga, S.; Łukowski, A.; Takayama, N. The effects of a short forest recreation program on physiological and psychological relaxation in young Polish adults. Forests 2019, 10, 34. [CrossRef] 
40. Lee, H.J.; Son, Y.H.; Kim, S.; Lee, D.K. Healing experiences of middle-aged women through an urban forest therapy program. Urban For. Urban Green. 2019, 38, 383-391. [CrossRef]

41. Song, C.; Ikei, H.; Kagawa, T.; Miyazaki, Y. Effects of walking in a forest on young women. Int. J. Environ. Res. Public Health 2019, 16, 229. [CrossRef]

42. Wang, X.; Shi, Y.; Zhang, B.; Chiang, Y. The Influence of Forest Resting Environments on Stress Using Virtual Reality. Int. J. Environ. Res. Public Health 2019, 16, 3263. [CrossRef]

43. Yu, C.P.S.; Hsieh, H. Beyond restorative benefits: Evaluating the effect of forest therapy on creativity. Urban For. Urban Green. 2020, 51, 126670. [CrossRef]

44. Huang, Q.; Yang, M.; Jane, H.A.; Li, S.; Bauer, N. Trees, grass, or concrete? The effects of different types of environments on stress reduction. Landsc. Urban Plan. 2020, 193, 103654. [CrossRef]

45. Kim, J.G.; Khil, T.G.; Lim, Y.; Park, K.; Shin, M.; Shin, W.S. The Psychological Effects of a Campus Forest Therapy Program. Int. J. Environ. Res. Public Health 2020, 17, 3409. [CrossRef] [PubMed]

46. Kuper, R. Preference and restorative potential for landscape models that depict diverse arrangements of defoliated, foliated, and evergreen plants. Urban For. Urban Green. 2020, 48, 126570. [CrossRef]

47. Sacchelli, S.; Grilli, G.; Capecchi, I.; Bambi, L.; Barbierato, E.; Borghini, T. Neuroscience Application for the Analysis of Cultural Ecosystem Services Related to Stress Relief in Forest. Forests 2020, 11, 190. [CrossRef]

48. Janeczko, E.; Bielinis, E.; Wójcik, R.; Woźnicka, M.; Kedziora, W.; Lukowski, A.; Elsadek, M.; Szyc, K.; Janeczko, K. When urban environment is restorative: The effect of walking in suburbs and forests on psychological and physiological relaxation of young polish adults. Forests 2020, 11, 591. [CrossRef]

49. Zeng, C.; Lyu, B.; Deng, S.; Yu, Y.; Li, N.; Lin, W.; Li, D.; Chen, Q. Benefits of a three-day bamboo forest therapy session on the physiological responses of university students. Int. J. Environ. Res. Public Health 2020, 17, 3238. [CrossRef]

50. Wang, Y.; Jiang, M.; Huang, Y.; Sheng, Z.; Huang, X.; Lin, W.; Chen, Q.; Li, X.; Luo, Z.; Lv, B. Physiological and psychological effects of watching videos of different durations showing urban bamboo forests with varied structures. Int. J. Environ. Res. Public Health 2020, 17, 3434. [CrossRef]

51. Bielinis, E.; Simkin, J.; Puttonen, P.; Tyrväinen, L. Effect of viewing video representation of the urban environment and forest environment on mood and level of procrastination. Int. J. Environ. Res. Public Health 2020, 17, 5109. [CrossRef]

52. Wang, R.; Zhao, J. Effects of evergreen trees on landscape preference and perceived restorativeness across seasons. Landsc. Res. 2020, 45, 649-661. [CrossRef]

53. Wickelmaier, F. An introduction to MDS. Sound Qual. Res. UnitAalb. Univ. Den. 2003, 46, 1-26.

54. Sacchelli, S.; Fabbrizzi, S.; Bernetti, I.; Menghini, S. State of the art of ecosystem services research at the global level: A multiscale quantitative review. Int. J. Environ. Sustain. Dev. 2017, 16, 359-378. [CrossRef]

55. Watson, D.; Clark, L.A.; Tellegen, A. Development and Validation of Brief Measures of Positive and Negative Affect: The PANAS Scales. J. Pers. Soc. Psychol. 1988, 54, 1063-1070. [CrossRef] [PubMed]

56. Hartig, T.; Lindblom, K.; Ovefelt, K. The home and near-home area offer restoration opportunities differentiated by gender. Scand. Hous. Plan. Res. 1998, 15, 283-296. [CrossRef]

57. Yu, C.-P.; Lee, H.-Y.; Luo, X.-Y. The effect of virtual reality forest and urban environments on physiological and psychological responses. Urban For. Urban Green. 2018, 35, 106-114. [CrossRef]

58. Lemyre, L. Psychological stress measure (PSM-9): Integration of an evidence-based approach to assessment, monitoring, and evaluation of stress in physical therapy practice. Physiother. Theory Pract. 2009, 25, 453-462. [CrossRef] [PubMed]

59. Lee, I.; Choi, H.; Bang, K.S.; Kim, S.; Song, M.K.; Lee, B. Effects of forest therapy on depressive symptoms among adults: A systematic review. Int. J. Environ. Res. Public Health 2017, 14, 321. [CrossRef]

60. Marušáková, L.; Sallmannshofer, M. Human Health and Sustainable Forest Management; Forest Europe: Zvolen, Slovakia, 2019.

(C) 2020 by the authors. Licensee MDPI, Basel, Switzerland. This article is an open access article distributed under the terms and conditions of the Creative Commons Attribution (CC BY) license (http://creativecommons.org/licenses/by/4.0/). 